\title{
Produção de protease colagenolítica por Bacillus stearothermophillus de solo amazônico
}

\author{
Lorena Azevedo LIMA ${ }^{1}$, Raimundo Felipe CRUZ FILHO², Januário Gama dos SANTOS², \\ Wilson Castro SILVA ${ }^{1,3^{*}}$ \\ 1 Universidade do Estado do Amazonas, Programa de Pós-graduação em Biotecnologia e Recursos Naturais da Amazônia, Manaus, AM - Brasil. \\ ${ }^{2}$ Universidade Federal do Amazonas - UFAM, Laboratório de Microbiologia, Departamento de Parasitologia, Manaus, AM - Brasil. \\ ${ }^{3}$ Universidade Nilton Lins, Programa de Pós-graduação em Biologia Urbana, Manaus, AM - Brasil. \\ *Corresponding author: sprinkler65@gmail.com

\section{RESUMO}

As proteases colagenolíticas são enzimas capazes de hidrolisar as ligaçôes peptídicas de vários tipos de colágeno e têm grande importância na medicina e em aplicaçōes terapêuticas. O objetivo desta pesquisa foi avaliar a produção de proteases colagenolíticas por Bacillus stearothermophilus. Os tratamentos foram realizados por meio de um planejamento fatorial completo $2^{3}$, a fim de avaliar a significância dos efeitos e interaçóes das variáveis - $\mathrm{pH}$ inicial, concentraçáo de substrato e temperatura - sobre a produção de protease colagenolítica. O ponto central foi executado em quadruplicata para fornecer uma estimativa dos erros experimentais. Ensaios enzimáticos com colágeno e azocaseína como substratos foram realizados para determinação das atividades colagenolítica e proteolítica respectivamente. A maior atividade enzimática colagenolítica foi 79,38 $\mathrm{U} \mathrm{mL}^{-1}$, correspondendo a atividade específica de $136,86 \mathrm{U} \mathrm{mg}^{-1}$, em condiçóes iniciais de fermentaçáo, na concentraçáo de substrato a $1 \%(\mathrm{p} / \mathrm{v}), \mathrm{pH}$ 7,2 e $25^{\circ} \mathrm{C}$. A atividade proteolítica da enzima foi mais ativa em $\mathrm{pH} 9,0$ e $50^{\circ} \mathrm{C}$ e foi estável nas faixas de $\mathrm{pH}(6,0-9,0)$ e temperatura $\left(45^{\circ} \mathrm{C}-50^{\circ} \mathrm{C}\right)$. Bacillus stearothermophilus apresenta viabilidade para a produção de proteases colagenolíticas e a obtenção dessas enzimas tem grande importância para aplicaçóes biotecnológicas.

PALAVRAS-CHAVE: enzimas bacterianas, colágeno, planejamento fatorial

\section{Production of collagenolytic protease by Bacillus stearothermophillus from an Amazonian soil}

\section{ABSTRACT}

Collagenolytic proteases are enzymes able of hydrolyzing the peptide bonds of several types of collagen, and have great importance in the medicine and therapeutic applications. The aim of this research was to evaluate the production of collagenolytic proteases by Bacillus stearothermophilus. Treatments were performed used a $2^{3}$ full factorial design, in order to evaluate the significance of the effects and interactions of variables - initial $\mathrm{pH}$, substrate concentration and temperature - on the production of collagenolytic protease. The central point was run in quadruplicate to provide an estimate of the experimental error. Enzyme assays with collagen and azocasein as substrates were performed to determine the collagenolytic and proteolytic activities respectively. The highest collagenolytic enzyme activity was $79.38 \mathrm{U} \mathrm{mL}^{-1}$, corresponding to a specific activity of $136.86 \mathrm{U} \mathrm{mg}^{-1}$, in the initial fermentation conditions, substrate concentration at $1 \%(\mathrm{w} / \mathrm{v}), \mathrm{pH} 7.2$ and $25^{\circ} \mathrm{C}$. Proteolytic activity of enzyme was most active at $\mathrm{pH} 9.0$ and $50^{\circ} \mathrm{C}$, and was stable over wide $\mathrm{pH}\left(6.0\right.$ - 9.0) and temperature ranges $\left(45^{\circ} \mathrm{C}-50^{\circ} \mathrm{C}\right)$. Bacillus stearothermophilus shows viability for the production of collagenolytic proteases, and the obtaining these enzymes have high importance for biotechnological applications.

KEYWORDS: bacterial enzymes, collagen, factorial design 


\section{INTRODUÇÃO}

As proteases colagenolíticas são enzimas capazes de hidrolisar as ligaçôes peptídicas de vários tipos de colágeno, que é a proteína mais abundante nos mamíferos. São de considerável importância na medicina e em aplicaçôes terapêuticas (Rao et al. 1998; Watanabe 2004).

As proteases colagenolíticas são utilizadas na degradação de tecido necrosado; remoção de cicatrizes hipertróficas; terapias de queimados; composição de pomadas cicatrizantes; prevenção de tratamento de lesôes (Kuşcu et al. 2002; Özcan et al. 2002); e em estudos pré-clínicos terapêuticos no retardamento de cirrose hepática em coelhos e fibrose pulmonar em camundongos (Jin et al. 2005; Ouchi et al. 2008), nos quais a ação das enzimas colagenolíticas ocorre pela indução da aplicação de antibiótico ou por administração veia porta de colagenases, respectivamente. As enzimas colagenolíticas apresentam grande potencial econômico, pois além das várias aplicaçôes na indústria farmacêutica, podem ser utilizadas no setor alimentício, na indústria cosmética, na indústria de couro e no setor agrícola para o biocontrole de nematoides (Lintner e Peschard 2000; Kanth et al. 2008).

Entre as várias fontes de proteases colagenolíticas, as proteases microbianas desempenham um papel importante nos processos biotecnológicos (Chu 1987). Alguns microorganismos, selecionados a partir do solo, água e caviar, como Bacillus alvei, Thermoactinomyces sp. e Bacillus sp. (Kawahara et al. 1993; Schallmey et al. 2004; Petrova et al. 2006), são considerados seguros para a produção de colagenase.

Aproximadamente, $60 \%$ das enzimas disponíveis comercialmente são produzidas por espécies de Bacillus, principalmente, sendo proteínas homólogas que são naturalmente secretadas para o meio de crescimento (Westers $e t$ al. 2004). Além disso, as estirpes de Bacillus têm a capacidade de produzir e secretar grandes quantidades $\left(20-25 \mathrm{~g} \mathrm{~L}^{-1}\right)$ de enzimas extracelulares e, dentre elas, as proteases são as mais presentes (Priest 1977), estando entre as mais importantes produtoras de enzimas industriais (Schallmey et al. 2004). O objetivo desta pesquisa foi avaliar as melhores condiçóes para a produçáo de proteases colagenolíticas por Bacillus stearothermophilus utilizando um planejamento e caracterizar a enzima sob as condiçōes mais favoráveis.

\section{MATERIAL E MÉTODOS}

\section{Micro-organismo e meio de cultura}

A amostra Bacillus stearothermophilus DPUA1729 do solo amazônico foi obtida da Coleçấo de Culturas do Departamento de Parasitologia da Universidade Federal do Amazonas (DPUA / UFAM). A cultura bacteriana foi ativada em caldo Mueller-Hinton e incubada durante 24 horas a 37
${ }^{\circ} \mathrm{C}$. Para a análise quantitativa da atividade proteolítica, a linhagem bacteriana foi inoculada em agar gelatina/leite a $1 \%(\mathrm{p} / \mathrm{v})$ e incubada a $37^{\circ} \mathrm{C}$ durante $24 \mathrm{~h}$. Em seguida, a linhagem foi inoculada em meio de cultivo contendo $0,25 \%$ de colágeno insolúvel. $\mathrm{O}$ meio de cultivo foi constituído de 0,5 g de $\mathrm{KH}_{2} \mathrm{PO}_{4}, 0,2 \mathrm{~g} \mathrm{MgSO}_{4} .7 \mathrm{H}_{2} \mathrm{O}, 0,1 \mathrm{~g} \mathrm{ZnSO} \mathrm{H}_{2} \mathrm{O}, 1 \mathrm{~g}$ de $\mathrm{NaCl}, 0,25 \%$ de colágeno insolúvel $(\mathrm{p} / \mathrm{v})$ de agar e $1,5 \%(\mathrm{p} / \mathrm{v})$, $\mathrm{pH} 7,2$ (Wu et al. 2010). Após $24 \mathrm{~h}$ de incubação a $37^{\circ} \mathrm{C}$, utilizou-se solução de Comassie brilliant blue G a 1\% (p/v), para revelação do halo enzimático (Doust e Morabez 2004).

\section{Análises bioquímicas}

Os tratamentos foram realizados por meio de um planejamento fatorial completo $2^{3}$, a fim de avaliar a significância dos efeitos e interaçóes das variáveis - $\mathrm{pH}$ inicial, concentração de substrato e temperatura - sobre a produção de protease colagenolítica. $\mathrm{O}$ ponto central foi executado em quadruplicata para fornecer uma estimativa dos erros experimentais (Tabela 1).

O planejamento fatorial e o gráfico de Pareto foram elaborados utilizando os programas estatísticos Minitab Statistical Software 16 (Minitab Inc, Pensilvânia, EUA). O meio de fermentaçáa foi composto de 2,0 $\mathrm{g} \mathrm{KH} \mathrm{PO}_{4}, 1,0 \mathrm{~g}$ (NH4) ${ }_{2} \mathrm{SO}_{4}, 0,1 \mathrm{~g} \mathrm{MgSO}_{4} .7 \mathrm{H} 2 \mathrm{O}, 0,9 \mathrm{~g} \mathrm{Na}_{2} \mathrm{HPO}_{4} \cdot 2 \mathrm{H}_{2} \mathrm{O}$ e $1,0 \mathrm{~g}$ de extrato de levedura e $0,1 \mathrm{~g} \mathrm{de} \mathrm{CaCl}_{2}$ dissolvidos em tampóes com diferentes $\mathrm{pH}$ (Tran e Nagano 2002), variando as concentraçóes de gelatina, conforme planejamento fatorial (Tabela 1). Os tampóes utilizados foram de citrato $(\mathrm{pH} 5,0$ a 6,0) $50 \mathrm{mM}$ e de Tris-HCl (pH 7,2) $50 \mathrm{mM}$. A partir da cultura-estoque foi preparada suspensão padronizada pela escala de MacFarland 1. Desta suspensão foram retirados 200 $\mu \mathrm{L}$ para inoculação em Erlenmeyer de $125 \mathrm{~mL}$, contendo 25 $\mathrm{mL}$ de meio de fermentaçáo (Lima et al. 2009). A cultura bacteriana foi submetida à agitação de $160 \mathrm{rpm}$ durante $24 \mathrm{~h}$ e as temperaturas foram estabelecidas de acordo com planejamento fatorial (Tabela 1). Após o período de agitação, o sobrenadante foi separado por centrifugação $10.000 \mathrm{x} \mathrm{g}$ durante 10 minutos e filtrado em membrana de $0,22 \mu \mathrm{m}$. Este filtrado foi nomeado por extrato bruto. A concentração de proteína foi determinada de acordo com método Bradford (1976), utilizando albumina de soro bovino como padrão. A absorvância foi medida a $595 \mathrm{~nm}$ e a unidade proteica foi expressa em $\mathrm{mg} \mathrm{mL}^{-1}$.

Tabela 1. Planejamento fatorial completo $2^{3}$ com quatro repetições no ponto central

\begin{tabular}{lccc}
\hline \multirow{2}{*}{ Fator } & \multicolumn{3}{c}{ Nível } \\
\cline { 2 - 4 } & -1 & 0 & +1 \\
\hline pH & 5,0 & 6,0 & 7,2 \\
Temperatura $\left({ }^{\circ} \mathrm{C}\right)$ & 25 & 37 & 45 \\
Concentração da gelatina $(\mathrm{p} / \mathrm{v})$ & 0,25 & 0,5 & 1,0 \\
\hline
\end{tabular}




\section{Ensaio enzimático}

O ensaio enzimático para determinação da protease colagenolítica foi realizado de acordo com o método desenvolvido por Moore e Stein (1948), com algumas modificaçóes. A mistura foi constituída de $0,2 \mathrm{~mL}$ do extrato bruto, $0,8 \mathrm{~mL}$ de solução contendo Tris- $\mathrm{HCl} 50 \mathrm{mM}, \mathrm{CaCl}_{2}$ $4 \mathrm{mM}$ e colágeno insolúvel a $1 \%(\mathrm{p} / \mathrm{v})$ nas faixas de $\mathrm{pH}$ estabelecidas pelo planejamento fatorial. Posteriormente, foi incubado durante 10 horas nas temperaturas estabelecidas pelo planejamento fatorial (Tabela 1). Após esse período, a reação foi interrompida pela adição de $0,2 \mathrm{~mL}$ de ácido tricloroacético a $10 \%(\mathrm{p} / \mathrm{v})$. Tubos contendo a mistura foram centrifugados a $10.000 \times \mathrm{g}$ por 10 minutos e o extrato enzimático foi filtrado em membrana de 0,22 $\mu \mathrm{m}$. Para determinar a atividade colagenolítica, uma unidade de grupo amino livre de colágeno foi mensurada pelo método de ninidrina, no qual $0,5 \mathrm{~mL}$ de soluçáo ninidrina a $2 \%$ (p/v) e $0,2 \mathrm{~mL}$ do sobrenadante foram aquecidos por 10 minutos. Em seguida, foram submetidos a resfriamento por cinco minutos. Foi feita uma diluição com $5 \mathrm{~mL}$ de 1 -propanol a $50 \%(\mathrm{p} / \mathrm{v})$. A mistura foi centrifugada a $12.000 \times \mathrm{g}$ durante 10 minutos e a absorbância foi medida em $570 \mathrm{~nm}$. A atividade colagenolítica foi expressa como um $\mu \mathrm{mol}$ de glicina equivalente liberado por minuto. A atividade colagenolítica específica foi calculada pela razão entre a atividade colagenolítica $\left(\mathrm{U} \mathrm{mL}^{-1}\right)$ e a proteína total $\left(\mathrm{mg} \mathrm{mL}^{-1}\right)$, e expressa em $\mathrm{U} \mathrm{mg}^{-1}$ (Tabela 2).

A atividade proteolítica foi determinada utilizando-se 150 $\mu \mathrm{L}$ do extrato bruto e como substrato $250 \mu \mathrm{L}$ de azocaseína a 1,0\% (p/v) (Sigma, St. Louis, MO USA), em tampão Tris- $\mathrm{HCl} 0,05 \mathrm{M} \mathrm{pH} 7,2$. A reaçáo foi mantida em câmara escura e após 60 minutos adicionou-se $1,2 \mathrm{~mL}$ de ácido tricloroacético a $10 \%(\mathrm{p} / \mathrm{v})$. O resíduo remanescente foi

Tabela 2. Produção de protease colagenolítica de $B$. stearothermophilus DPUA1729 no planejamento fatorial $\left(2^{3}\right) . \mathrm{pH}=\mathrm{pH}$ inicial do meio; $\mathrm{T}=$ temperatura; $\mathrm{S}=$ concentração de substrato; $\mathrm{Ac}=$ Atividade colagenolítica; PT $=$ proteína total; $\mathrm{Ae}=$ Atividade colagenolítica específica. ${ }^{*}$ pontos centrais

\begin{tabular}{lcccccc}
\hline & $\mathrm{pH}$ & $\begin{array}{c}\mathrm{T} \\
\left({ }^{\circ} \mathrm{C}\right)\end{array}$ & $\begin{array}{c}\mathrm{S} \\
(\%)\end{array}$ & $\begin{array}{c}\mathrm{Ac} \\
\left(\mathrm{U} \mathrm{mL}^{-1}\right)\end{array}$ & $\begin{array}{c}\mathrm{PT} \\
\left(\mathrm{mg} \mathrm{mL}^{-1}\right)\end{array}$ & $\begin{array}{c}\mathrm{Ae} \\
\left(\mathrm{U} \mathrm{mg}^{-1}\right)\end{array}$ \\
\hline 1 & 5,0 & 25 & 0,25 & 35,20 & 0,38 & 92,63 \\
2 & 7,2 & 25 & 0,25 & 29,14 & 0,43 & 67,77 \\
3 & 5,0 & 45 & 0,25 & 15,95 & 0,04 & 398,75 \\
4 & 7,2 & 45 & 0,25 & 15,20 & 0,59 & 25,76 \\
\hline 5 & 5,0 & 25 & 1,00 & 44,04 & 0,14 & 314,57 \\
6 & 7,2 & 25 & 1,00 & 79,38 & 0,58 & 136,86 \\
7 & 5,0 & 45 & 1,00 & 19,78 & 0,13 & 152,15 \\
\hline 8 & 7,2 & 45 & 1,00 & 16,36 & 0,06 & 272,67 \\
\hline $9^{*}$ & 6,0 & 37 & 0,50 & 39,10 & 0,22 & 177,73 \\
\hline $10^{*}$ & 6,0 & 37 & 0,50 & 39,28 & 0,26 & 151,07 \\
\hline $11^{*}$ & 6,0 & 37 & 0,50 & 40,40 & 0,22 & 183,64 \\
$12^{*}$ & 6,0 & 37 & 0,50 & 43,18 & 0,30 & 143,93 \\
\hline
\end{tabular}

removido por centrifugaçáo $(8.000 \times \mathrm{g})$ a $4^{\circ} \mathrm{C}$ por 10 minutos. Do sobrenadante foram retirados $0,8 \mathrm{~mL}$ e adicionados a 1,4 $\mathrm{mL}$ de hidróxido de sódio $1 \mathrm{M}$, procedendo-se a leitura a 440 nm. Uma unidade de atividade proteásica foi definida por Leighton et al. (1973) como a quantidade de enzima necessária para produzir uma variação de absorbância igual a 0,1 em 60 minutos, sendo expressa em $\mathrm{U} \mathrm{mL}^{-1}$.

\section{Efeitos do $\mathrm{pH}$ e da temperatura sobre a atividade e a estabilidade proteolítica}

A temperatura ótima para atividade da enzima foi determinada utilizando $250 \mu \mathrm{L}$ de azocaseína a $1 \%(\mathrm{p} / \mathrm{v})$ em Tris- $\mathrm{HCl}(\mathrm{pH} 7,2) 50 \mathrm{mM} \mathrm{e} 0,8 \mathrm{~mL}$ do extrato. Os meios reacionais foram incubados nas temperaturas de $25,37,45$, 50,60 e $80^{\circ} \mathrm{C}$ durante 60 minutos. O pH ótimo para medida da atividade enzimática foi determinado variando-se o $\mathrm{pH}$ do meio reacional na faixa de $\mathrm{pH}$ entre 5,0 e 10,0. Os tampóes utilizados foram de citrato $(5,0$ a 6,0$) 50 \mathrm{mM}$, de Tris-HCl (pH 7,2 a 9,0) 50 mM e de carbonato-bicarbonato de sódio (pH 10,0) 50 mM. A estabilidade de temperatura foi realizada a $45^{\circ} \mathrm{C}$ e estabilidade do $\mathrm{pH}$ foi realizada na faixa 7,2 , ambas foram mantidas por 105 minutos, a atividade enzimática foi expressa em atividade relativa. Todos os experimentos foram realizados em triplicata.

\section{RESULTADOS}

\section{Produção de protease colagenolítica}

Em meio agar gelatina leite e Agar colágeno observou-se as atividades proteolítica e colagenolítica produzidas por B.stearothermophilus DPUA 1729, respectivamente, reveladas pela formaçáo de halos translúcidos ao redor da colônia.

A maior atividade enzimática colagenolítica foi 79,38 $\mathrm{U} \mathrm{mL}^{-1}$, correspondendo a atividade específica de 136,86 U $\mathrm{mg}^{-1}$, em condiçôes iniciais de fermentação: na concentração de gelatina a $1 \%(\mathrm{p} / \mathrm{v}), \mathrm{pH} 7,2$ e $25^{\circ} \mathrm{C}$. O valor de menor atividade enzimática foi $15,20 \mathrm{U} \mathrm{mL}^{-1}$, com atividade específica de $25,59 \mathrm{U} \mathrm{mg}^{-1}$, em condiçôes iniciais de fermentação: na concentração de gelatina a $0,25 \%(\mathrm{p} / \mathrm{v}), \mathrm{pH}$ 7,2 e $45^{\circ} \mathrm{C}$ (Tabela 2).

O gráfico de Pareto representa os efeitos estimados das variáveis e suas interaçôes sobre a atividade colagenolítica. O comprimento da barra é proporcional ao efeito padronizado. A linha vertical pode ser usada para avaliar quais efeitos são significativos estatisticamente. As barras que se estendem para além desta linha correspondem aos efeitos que foram estatisticamente significativos $(\alpha=0,05)$. Pode ser visto a partir da Figura 1, que o efeito foi significativo para todas as variáveis nas quais, o fator $\mathrm{A}$ ( $\mathrm{pH}$ inicial) e fator $\mathrm{C}$ (concentração de substrato) apresentaram efeito positivo significativo, indicando que o aumento desses valores melhora a produção 
de colagenase. No entanto, o fator B (temperatura de fermentaçáo) apresentou influência negativa $(-22,5881)$, indicando melhor produção enzimática com a variação abaixo do menor nível de temperatura utilizada neste planejamento.

\section{Efeito e estabilidade do $\mathrm{pH}$ sobre a protease}

No efeito do $\mathrm{pH}$ sobre a atividade proteolítica de $B$. stearothermophilus DPUA 1729 verificou-se atividade na faixa de $\mathrm{pH}(5,0$ a 10,0) durante $60 \mathrm{~min}$. A atividade máxima do extrato da enzima foi em pH 9,0 (Figura 2A). Entretanto, $80 \%$ da atividade da protease foi mantida no intervalo de $\mathrm{pH} 7,2$ - 9,0, e mais de $60 \%$ desta atividade foi entre $\mathrm{pH} 6,0$ a 10,0. A estabilidade da enzima foi mantida acima de $66 \%$ em faixas de $\mathrm{pH} 6,0$ a 9,0, com redução menor que $20 \%$ em pH 10,0 (Figura 2B).

\section{Efeito e estabilidade da temperatura sobre a protease}

Os dados referentes ao efeito da temperatura sobre a atividade proteolítica de B. stearothermophilus DPUA1729 apresentaram máxima atividade enzimática a $50^{\circ} \mathrm{C}$. O perfil da atividade proteolítica versus variação de temperatura manteve mais de $80 \%$ de ação enzimática entre 45 e $50^{\circ} \mathrm{C}$. Contudo, o aumento da temperatura acima de $60^{\circ} \mathrm{C}$ reduziu a atividade da protease abaixo de $20 \%$ (Figura 3A).

$\mathrm{Na}$ avaliação da estabilidade da atividade proteolítica após a incubaçáo do extrato bruto por 105 minutos em diferentes temperaturas, observou-se a atividade enzimática em todas as temperaturas testadas $\left(25^{\circ} \mathrm{C}-80^{\circ} \mathrm{C}\right)$. A estabilidade para o extrato de B. stearothermophillus DPUA1729, em relação à

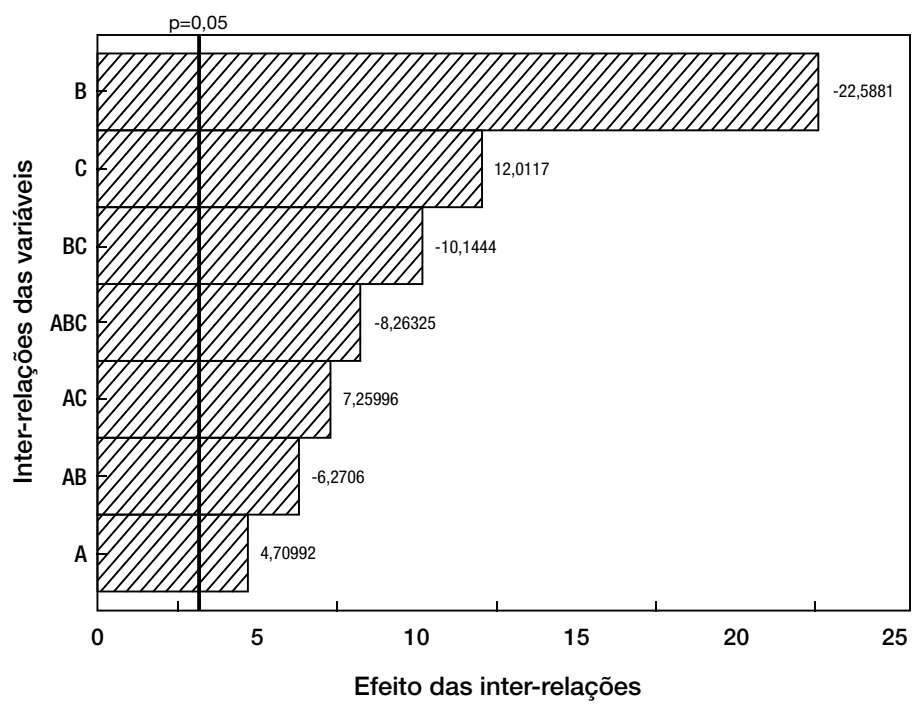

Figura 1. Gráfico de Pareto definindo as inter-relações entre as variáveis independentes, demonstrando a afinidade entre as escalas mais elevadas das interrelações. $\mathrm{A}=\mathrm{pH}, \mathrm{B}=$ Temperatura e $\mathrm{C}=$ Concentração do substrato
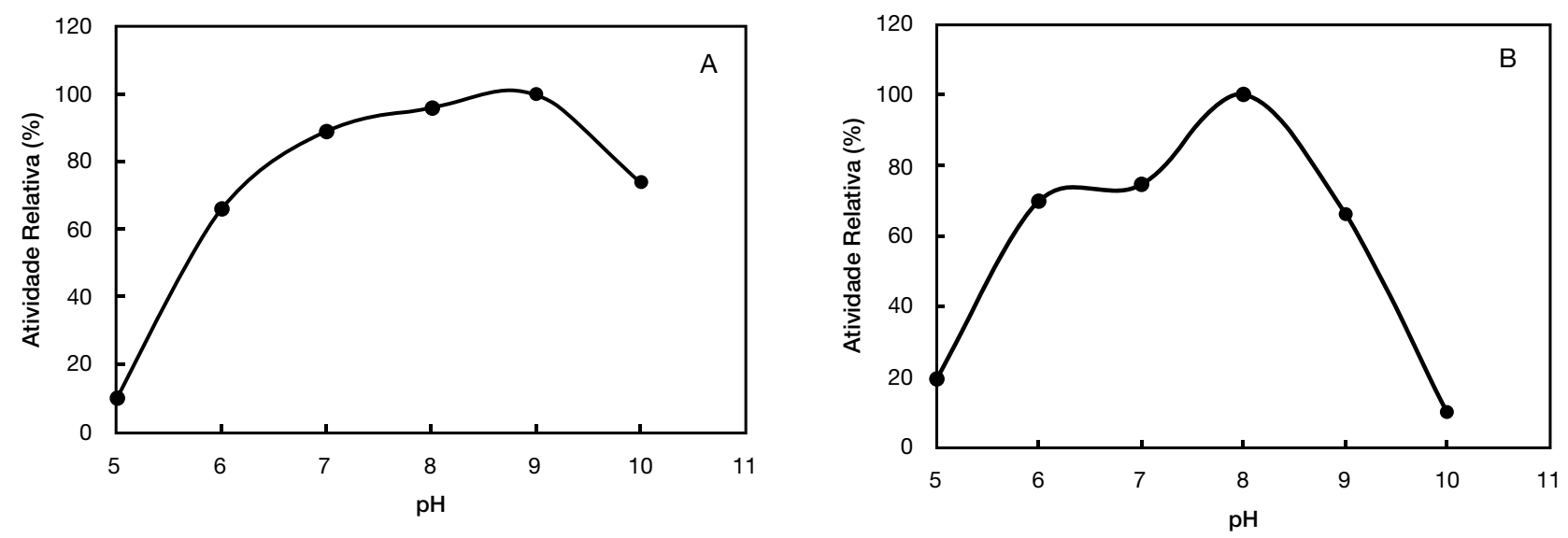

Figura 2. (A) Efeito do pH sobre a atividade da protease extracelular e (B) Estabilidade da enzima em diferentes pH 


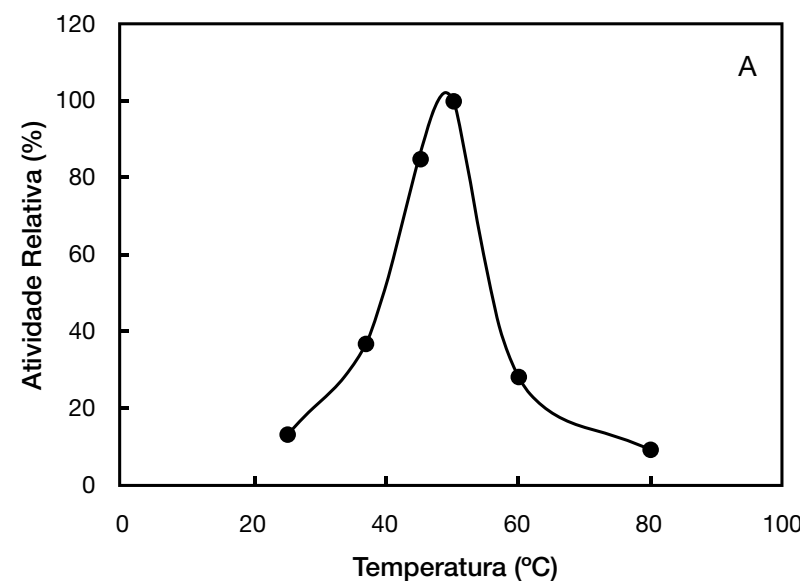

Figura 3. (A) Efeito da temperatura sobre a atividade da protease extracelular e

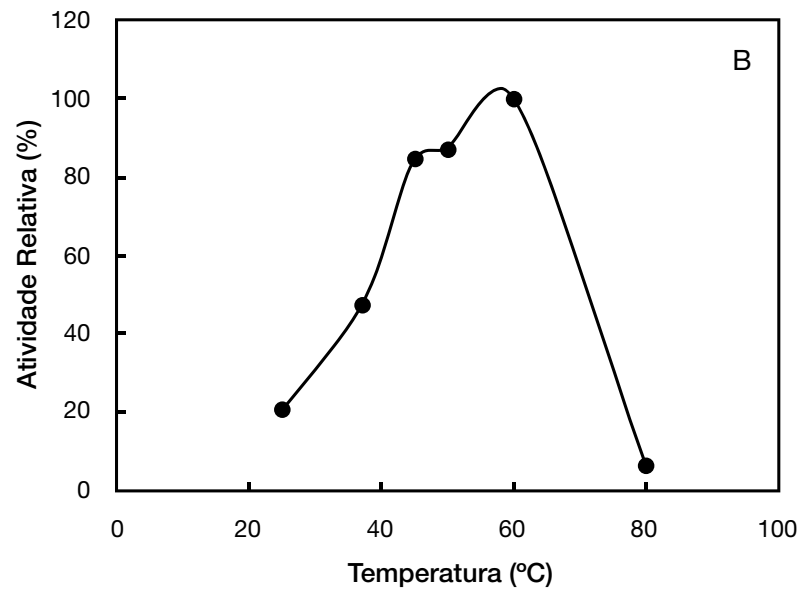

(B) Estabilidade da enzima em diferentes temperaturas temperatura, manteve-se acima de $85 \%$ da atividade relativa (Figura 3B).

\section{DISCUSSÃO}

A atividade colagenolítica máxima por $B$. stearothermophilus DPUA 1729 foi cinco vezes maior que a atividade mínima, confirmando que a temperatura e a concentração de substrato foram os fatores que mais influenciaram na produção de colagenase (Tabela 2 e Figura 1). A temperatura é um dos mais importantes parâmetros que devem ser controlados em um bioprocesso (Chi e Zhao 2003). Observou-se que a temperatura foi o fator que influenciou na atividade colagenolítica, mostrando que a temperatura é inversamente proporcional a produção de protease, ou seja, quanto menor a temperatura maior a atividade enzimática.

A atividade colagenolítica por $B$. stearothermophilus DPUA 1729 foi superior à atividade obtida por Suphatharaprateep et al. (2011), que utilizaram Bacillus cereus CNA1 em condições similares de fermentação: $\mathrm{pH} 7,5$ com $1 \%(\mathrm{p} / \mathrm{v})$ de concentração de gelatina a $37^{\circ} \mathrm{C}$. Estes resultados implicam que cada micro-organismo tem suas características físicoquímicas e exigências nutricionais para o crescimento e produção enzimática (Readdy et al. 2008) confirmando que não há meio geral para a produção de protease por diferentes estirpes microbianas (Pandey et al. 2000).

A produção enzimática por B. stearothermophilus DPUA 1729 pode ser induzida pelo aumento da concentraçáo de gelatina no meio. Lima et al. (2011) realizaram um estudo de otimização do meio de cultura e condiçóes de cultivo para a produção de colagenase por Penicillum aurantiogriseum URM 4622, e observaram que houve influência da variação de concentração de substrato, no entanto, o fator temperatura mostrou efeito negativo na produção enzimática. $\mathrm{O}$ fator temperatura no nosso estudo, também, apresentou efeito negativo, provavelmente, a melhor produção enzimática ocorre em baixas temperaturas, mantendo adequado o fluxo metabólico sob condiçóes de estresse.

As proteases colagenolíticas produzidas por $B$. stearothermophilus DPUA1729 possuem baixa tolerância à temperatura em pH com baixa alcalinidade (tabela 2). Em estudos realizados por Zambare et al. (2011), observou-se que a baixa temperatura apresentou influência na atividade colagenolítica por Pseudomonas aeruginosa MCM-327, atuando em $\mathrm{pH}$ neutro. Estes resultados, possivelmente, se ajustam ao fato de que as proteases com baixa tolerância de temperatura são consideradas proteases bacterianas neutras e são ativas na faixa de pH 5,0 a 8,0 (Rao et al. 1998).

Em relação ao efeito do $\mathrm{pH}$ sobre a atividade enzimática, os resultados obtidos nesta pesquisa mostram que no $\mathrm{pH}$ alcalino ocorre maior produçáo de protease. Vários autores reportam a maior produção enzimática nesta faixa de $\mathrm{pH}$. Lima et al. (2011), na produção de proteases por Penicillium aurantiogriseum URM 4622, a atividade máxima foi expressa em pH 9,0 e mais de 60\% da maior atividade foi mantida no intervalo de pH 5,0-10,5. Sakurai et al. (2009) e Lima et al. (2009) utilizando Streptomyces parvulus e Candida albicans, respectivamente, obtiveram máxima produção de protease em pH 8,0; e Petrova et al. (2006) com Streptomyces sp. verificaram atividade proteolítica máxima em $\mathrm{pH} 7,5$. Observou-se que o $\mathrm{pH}$ tem efeito sobre a atividade enzimática na faixa alcalina, na qual ocorreu a maior produção de protease, mostrando a influência da concentração do ânion diatômico $\left(\mathrm{OH}^{-}\right)$. $\mathrm{O}$ efeito do $\mathrm{pH}$ na velocidade das reaçôes enzimáticas pode ser devido às alteraçôes da estabilidade da enzima, da afinidade da enzima para o substrato e da transformação catalítica em si. Estes três fatores podem atuar de um modo isolado ou 
combinado. Entretanto, deve-se levar em consideraçáo que $\mathrm{pH}$ muito elevado pode diminuir a estabilidade da enzima (Ferro 2002).

$\mathrm{Na}$ estabilidade do $\mathrm{pH}$ da protease por B. stearothermophilus DPUA1729 é possível observar que a enzima apresentou atividade enzimática em todos os $\mathrm{pH}$ iniciais no meio de fermentação. Petrova et al. (2006) e Sela et al. (1998) reportaram a estabilidade de $\mathrm{pH}$ de duas proteases colagenolíticas produzidas por Thermoactinomyces sp. (faixas de $\mathrm{pH} 6,5-9,0$ ) e por Bacillus cereus (faixas de $\mathrm{pH}$ 5,6-8,2) respectivamente. Estes estudos inferem que essas proteases são altamente estáveis em situações diversas de $\mathrm{pH}$ e íons.

O efeito da temperatura tem uma relação direta com a sobre a atividade enzimática. Observou-se que a temperatura ótima resultou em uma atividade enzimática relativamente alta (Figura 3A), ativa por 60 minutos. No estudo de Nagano e To (1999) com Bacillus subtilis FS-2 a protease teve uma temperatura ótima a $50{ }^{\circ} \mathrm{C}$, entretanto, essa enzima foi ativa por 30 minutos. Lima et al. (2009), com Candida albicans URM3622, observaram atividades ótimas sobre a produção de protease a $45^{\circ} \mathrm{C}$. Observa-se que a alta temperatura é um fator que favorece a produção de protease. Entretanto, a influência da temperatura na cinética da reação enzimática deve ser considerada, pois temperaturas elevadas causam a desnaturação da enzima pelo rompimento das ligaçóes de hidrogênio (Borzani et al. 2001).

Os resultados do nosso trabalho mostram que atividade proteolítica foi relativamente alta e a estabilidade da temperatura manteve-se por muito mais tempo (Figura 3B), comparadas com outros trabalhos com proteases microbianas. No trabalho de Nagano e To (1999) a produção de protease por Bacillus subtilis FS-2 manteve-se por 30 minutos, nas faixas entre $55^{\circ} \mathrm{C} \mathrm{a} 60{ }^{\circ} \mathrm{C}$. Os resultados obtidos por Suphatharaprateep et al. (2011), usando proteases de Bacillus cereus CNA1 e Klebsiella pneumoniae CNL3, as quais foram submetidas a temperatura de $50{ }^{\circ} \mathrm{C}$ durante 60 minutos, apresentou atividade relativa inferior a $60 \%$ e, quando incubadas a $55^{\circ} \mathrm{C}$, apresentaram $40 \%$ da atividade relativa. Em temperatura extremas, como $25^{\circ} \mathrm{C}$ e $80^{\circ} \mathrm{C}$, a atividade enzimática de B. stearothermophillus DPUA1729 apresentou um decréscimo inferior a 20\%. Contudo, a enzima se mostrou termoestável, podendo ser usada nos mais variados processos industriais.

\section{CONCLUSÕES}

A produção de enzimas colagenolíticas foi influenciada pelos fatores $\mathrm{pH}$ e concentração de substrato. Entretanto, nos níveis mais baixos de temperatura, houve maior produção. Bacillus stearothermophilus DPUA 1729 apresenta viabilidade para a produção de proteases colagenolíticas e a obtenção dessas enzimas tem grande importância para aplicaçôes biotecnológicas, podendo ser interessante para as indústrias de alimentos, farmacêutica, cosmética e em processos que utilizam colágeno e couro.

\section{AGRADECIMENTOS}

À Fundação de Amparo à Pesquisa do Estado do Amazonas (FAPEAM), pela concessão da bolsa de Mestrado.

\section{BIBLIOGRAFIA CITADA}

Borzani, W.; Schimidell, W.; Lima, U.A.; Aquarone, E. 2001. Biotecnologia Industrial: Fundamentos. 1 ed. Edgard Blücher Ltda, São Paulo, 2001, 288p.

Bradford, M.M. 1976. A rapid and sensitive method for the quantitation of microgram quantities of protein utilizing the principle of proteindye binding. Analytical Biochemistry, 72: 248-254.

Chi, Z.; Zhao, S. 2003. Optimization of medium and cultivation conditions for pullulan production by a new pullulan-producing yeast. Enzyme and Microbial Technology, 33: 206-221.

Chu, K.H. 1987. Collagenase chemonucleolysis via epidural injection. A review of 252 cases. Clinical Orthopaedics and Related Research, 215: 99-104.

Doust, R.H.; Mobarez, A.M. 2004. Collagenase activity in Prevotella Bivius Isolated from patients with premature rupture of membranes. Medical Journal of the Islamic Republic of Iran, 18: 61-66.

Ferro, L.A. 2002. Produção, purificação e caracterização da enzima B-1,3 glucanase de Cellulomonas cellulans YLM-B191-1 e ação da enzima na parede celular de leveduras. Tese de Doutorado, Universidade Estadual de Campinas, Campinas, São Paulo, 175p.

Jin, B.H.J.; Alter, Z.C.; Zhang, J.W.; Shih, J.M.; Esteban, T.; Sun, Y.S. et al. 2005. Reversibility of experimental rabbit liver cirrhosis by portal collagenase administration. Laboratory Investigation, 85: 992-1002.

Kanth, S.V.; Venba, R.; Madhan, B.; Chandrababu, N.K.; Sadulla, S. 2008. Studies on the influence of bacterial collagenase in leather dyeing. Dyes and Pigments, 76: 338-347.

Kawahara, H.; Kusumoto, M.; Obata, H. 1993. Isolation and Characterization os a New Type of Collagenase Producing Bacterium, Bacillus alvei DC-1. Bioscience, Biotechnology and Biochemistry, 57: 1372-1373.

Kuşcu, N.K.; Koyuncu, F.; Laçin, S. 2002. Collagenase treatment of sore nipples. International Journal of Gynecology \& Obstetrics, 76: $81-82$.

.Leighton, T.J.; Doi, R.H.; Warren, R.A.J.; Kelln, R.A. 1973. The relationship of serine protease activity to RNA poly-merase modification and sporulation in Bacillus subtilis. Journal Molecular Biology, 76: 103-122.

Lima, C.A.; Rodrigues, P.M.B.; Porto, T.S.; Viana, D.A.; Lima Filho, J.L.; Porto, A.L.F.; Cunha, M.G.C. 2009. Production of a collagenase from Candida albicans URM362. Biochemical Engineering Journal, 43: 315-320.

Lima, C.A.; Rodrigues, P.M.B.; Lima Filho, J.L.; Neto, B.B.; Converti, A.; Cunha, M.G.; Porto, A.L.F. 2011. Production 
and Characterization of a Collagenolytic Serine Proteinase by Penicillium aurantiogriseum URM 4622: A Factorial Study. Biotechnology and Bioprocess Engineering, 16: 549-560.

Lintner, K.; Peschard, O. 2000. Biologically active peptides: from a laboratory bench curiosity to a functional skin care product. International Journal of Cosmetic Science, 22: 207-218.

Moore, S.; Stein, W.H. 1948. Photometric ninhydrin method for use in the chromatography of amino acids. The Journal of Biologycal Chemistry, 176: 367-388.

Nagano, H.; To, K.A. 1999. Purification of Collagenase and Specificity it related enzyme from Bacillus subtilis FS-2, Bioscience, Biotechnology and Biochemistry, 63:181-183.

Ouchi, H.; Fujita, M.; Ikegame, S.; Ye, Q.; Inoshima, I.; Harada, E. et al. 2008. The role of collagenases in experimental pulmonary fibrosis. Pulmonary Pharmacology \& Theraeuthics, 21: 401-408.

Özcan, C.; Ergüno, C.; Elik, M.; Çördük, N.; Özok, G. 2002. Enzymatic debridement of burn wound with collagenase in children with partial-thickness burns. Burns, 28: 791-794.

Pandey, A.; Nigam, P.; Soccol, C.R.; Soccol, V.T.; Singh, D.; Mohan, R. 2000. Advances in microbial amylases, Biotechnology Applied Biochemistry, 1: 135-152.

Petrova, D.H.; Shishkov, S.A.; Vlahov, S.S. 2006. Novel thermostable serine collagenase from Thermoactinomyces sp. 21E: Purification and some properties. Journal Basic Microbiology, 46: 275-285.

Priest, F.G. 1977. Extracellular enzyme synthesis in the genus Bacillus. Bacteriological Reviews, 41: 1847-1881.

Rao, M.B.; Tanksale, A.M.; Ghatge, M.S.; Deshpande, V.V. 1998. Molecular and Biotechnological Aspects of Microbial Proteases. Microbiology Molecular Biology Reviews, 62: 597-635.

Readdy, L.V.A.; Wee, Y.J.; Yun, J.S.; Ryu, H.W. 2008. Optimization of alkaline protease production by batch culture of Bacillus sp. RKY3 through Plackett-Burman and response surface methodological approaches, Bioresource Technology, 99: 2242-2249.
Sakurai, Y.; Inoue, H.; Nishii, N.; Takahashi, Y.; Lino, Y.; Yamamoto, M.; Takahashi, K. 2009. Purification and characterization of a major collagenase from Streptomyces parvulus. Bioscience, Biotechnology and Biochemistry, 73: 21-28.

Sela, S.; Schickler, H.; Chet, I.; Spiegel, Y. 1998. Purification and characterization of a Bacillus cereus collagenolytic/proteolytic enzyme and its effect on Meloidogyne javanica cuticular proteins. European Journal of Plant Pathology, 104: 59-67.

Schallmey, M.; Singh, A. Ward, O.P. 2004. Developments in the use of Bacillus sp. for industrial production. Canadian Journal of Microbiology, 50: 1-17.

Suphatharaprateep, W.; Cheirsilp, B.; Jongjareonrak, A. 2011. Production and properties of two collagenases from bacteria and their application for collagen extraction. New Biotechnology, 28: 649-655.

Tran, K.A.; Nagano, H. 2002. Isolation and characteristics of Bacillus subtilis CN2 and its collagenase production. Journal Food Science, 67: 1184-1187.

Watanabe, K. 2004. Collagenolytic proteases from bacteria. Applied Microbiology and Biotechnology, 63: 520-526.

Westers, L.; Westers, H.; Quax, W.J. 2004. Bacillus subtilis as cell factory for pharmaceutical proteins: a biotechnological approach to optimize the host organism. Biochimica et Biophysica Acta, 1694: 299-310.

Wu, Q.; Li, C.H.; Li, C.; Chen, H.; Shuliang, L. 2010. Purification and Characterization of a Novel Collagenase from Bacillus pumilus Col-J. Applied Biochemistry and Biotechnology, 160: 129-139.

Zambare, V.; Nilegaonkar, S.; Kanekar, P. 2011. A novel extracellular protease from Pseudomonas aeruginosa MCM B-327 enzyme production and its partial characterization, New Biotechnology, 28: 173-181.

Recebido em 10/10/2013

Aceito em 07/03/2014 
